\title{
The Analysis of Transitivity in some Discourses in the Bali Times
}

\author{
Ida Bagus Astika Pidada ${ }^{1}$, Baiq Mandalika Adawiyah ${ }^{2}$ \\ Faculty of Letters, Universitas Warmadewa Denpasar-Bali, Indonesia ${ }^{1,2}$ \\ \{astika.pidada@gmail.com¹, adawiyah@gmail.com² ${ }^{2}$,
}

\begin{abstract}
This study is related to the types of processes and the roles of participants in each process found in Bali Times News. Hence, this study aims to find out the types of process derived from the transitivity analysis on the texts and to find out roles of the participant on that transitivity analysis on the texts. The data of this study were collected by reading newspaper and identifying the sentences relating to the problems. Then, the data were analyzed based on theory of transitivity by Halliday of Functional Grammar (1985). The data which are collected through library research method is analyzed by using descriptive method. Based on the analysis, it was found that five types of process found in data sources, they are (1) material process, (2) mental process, (3) relational process, (4) verbal process, (5) existential process. The roles of participants in material process are actor, goal, range, and recipient. The roles of participants found in mental process are senser and phenomenon. The participants of relational process as intensive process are carrier and attribute, identified (token) and identifier (value). The participants of relational process as circumstantial are carrier and attribute. The participants of relational process as possessive are carrier and attribute. The participants of verbal process are sayer and verbiage, and the participant of existential process is existent.
\end{abstract}

Keywords: Types of Process; Roles of Participants; Transitivity

\section{Introduction}

As a result of the presence of the variety, language varies not only according to who is talking its users yet additionally according to circumstance where happens its uses, it is without a doubt that between the listener and the speaker frequently happens misconception, particularly when the two of members are altogether non-local speaker in the communication. Also, misperception based on what is implied by the writer to what exactly is accepted by the reader in writing media. For the reasons, to assist us with seeing how messages work to make significance is required a model of language. Functional grammars see language as an asset for making meaning. These grammars attempt to depict language in genuine use and spotlight on messages and their specific circumstances, either setting of culture or setting of circumstance, to encourage student's interpretation and creation of text.

News thing recounts the event in form of summary. Moreover, it contains numerous processes, expounds what occur to whom, in what conditions. To give the audience a depiction 
of what is happened and when it happened is the function of a news thing. Newspaper ordinarily applies the new thing and it incorporates headliners, elaboration and remarks from the authorities/sources. This study is analysing those linguistic features of news item according to system of Transitivity. The various type of process determined by transitivity that the perceived in the language and structures by which they are communicated [1].

A clause is defined as a composite affair, a combination of three different structures deriving from functional components, they are clause as representation, clause as exchange and clause as message. Clause as representation (the ideational) is transitivity structures which express representation meaning: what the condition is about, which is regularly some process, with related participants and conditions. The verb and traditionally verb realizes process had been had been characterized as action words, however a few verbs are not action words at everything except rather express conditions or having.

The verbal gathering in the clause and the focal part of the message from the ideational perspective communicates a process. As we know process consists of process itself, participants and circumstances. There are three different process types in English clause, those are material processes, mental processes and relational processes. In addition, to these very large categories to recognize three others are needed, subsidiary types: behavioural processes, verbal processes and existential processes. The substances associated with the process e.i sayer, actor, and senser are called as participants. Circumstances are specifying the when, where, why and how of the process [1].

This study previously has been conducted [2], the results showed that there are six processes with different function appear in the speech, namely material processes, relational processes, existential processes, behavioral processes, mental processes, and verbal processes. In addition, other previous study [3] also showed the similar processes appear in the poetry. Another similar study conducted [4], showed that the clause effectively can analyzed by transitivity system. The experiences of the world recognized and encoded through transitivity system. The process appear in transitivity system are material, mental, relational, verbal, existential, and behavioral. Thus, based on the background and the latest related studies above, this study aims to find out the types of process derived from the transitivity analysis of the texts and to find out the roles of the participant on that transitivity analysis of the texts.

\section{Method}

This study applied the descriptive method which means that all of representative data were qualitatively analyzed based on the kinds of process find in the data. The data used in this study taken from the Bali Times News. Library research is applied in collecting the data. In addition, the data sources are taken from some books and website. The data were in the form of sentences and then it was classified based on the types of process in those data. The analysis is done by applying the theory of process proposed by Halliday.

\section{Results and Discussion}

This study discussed transitivity found in the Bali Times News. The analysis of the clauses from The Bali Times News is presented based on each process and participant type intransitivity. The theory used to analyze the collected data is the theory of transitivity proposed by Halliday. The discussion in this study consists of the kinds of types of process and 
participant found in The Bali Times News. The discussion is further analyzed and described below.

\subsection{Material Process and Its Participants}

The material processes use two participants, they are actor and goal. Besides, the material process may have other participants, such as range and recipient. The analysis of the material processes can be explained with the example below.

\section{a) Material Process with Actor and Goal}

The material process may carry two participants. They are as actor and goal. Based on the analysis, it was found the clauses related to this type of process. The example is explained below:

I Dewa Budjana, musician and guitarist from Indonesia will build museum 'Gitarku' in the area Ubud, Bali. (10-15:3)

The example above shows that the clause is formed by verb stating material process. It is expressed by the verb phrase will build, because the verb phrase refers to the activity done by participant. Here the material process carries two participants. The participant which comes before verb phrase is filled by the noun phrase I Dewa Budjana, musician and guitarist from Indonesia. It plays the role of the actor because this noun phrase does activity of stated by the verb. The second participant comes after the process. It is expressed by noun phrase museum 'Gitarku' in area of Ubud, Bali. This noun phrase plays the role as goal because it gets the effect of the process by Actor.

\section{b) Material Process with Actor and Range}

The role of the range is determined by the verb phrase which forms the clause. The example found is explained as follows:

Haris Riverview Kuta-Bali hosted a community blood drive in partnership with Bali Hotel Association and Bali Red Cross on December 4th 2015 from 9 am-12 am. (12-15:1)

Based on the example above, it can be seen that the material process which realized by the verb hosted, because it is happening something. This verb carries two participants, Haris Riverview Kuta-Bali and a community blood drive in partnership with Bali Hotel Association and Bali Red Cross on December 4th 2015 from 9 am-12 am. The noun phrase after verb plays the role of the actor because this participant does activity. After the verb plays the role as a range because the actor doesn't give an effect to the participant after the verb.

\section{c) Material Process with Goal and Recipient}

The material process can also have participants who play the role as goal and recipient. Based on analysis, it was found clauses formed by material process which have participants as actor and recipient. The example found is explained below:

The proceeds from all ticket sales will be donated directly to UNICEF and channelled to a project that vaccinates and educates impoverished children across the Asia Pacific region. (1015: 2)

Based on the example above, the material process is expressed by the verb phrase will be donated, because it is doing something. The noun phrase UNICEF is as recipient, because it 
gets benefit from the process giving. The clause The proceeds from all ticket sales is as Goal, because it gets effect from the participant actor, although in this clause no actor in this structure, but it is understood that the actor is who give the contribution.

\subsection{Mental Process and its Participant}

Senser and Phenomenon are two roles of participants in mental processes. Further explanation is about mental process kind.

\section{a) Affection and its Participant}

Process of affection is expressed by the verb phrase like feeling, liking, fearing and loving. This process gives affection in the senser. It was found clauses formed by mental process of affection.

I felt like I've done everything right. (10-15: 16)

The example above shows that the process of affection is expressed by the verb felt. The process felt can be categorized as a process of affection, because it expresses meaning of affecting, in this case gives the effect of feeling to the senser. The first participant which comes before the process is filled by noun phrase $I$. This noun phrase plays the role as senser because the noun phrase $I$ experience the feeling. The noun phrase like I've done everything right plays the role as phenomenon because it shows that it is the thing felt by the senser $I$.

\section{b) Cognition and its Participant}

The cognition process also carries the participant based on the concept of mental process. Here is an example of the mental process.

At the time she did not understand what happened in her northwestern Durango state hamlet on October 6. (10-15: 9)

Based on the concept of the cognition process, the example above uses the process of cognition which is expressed by the verb phrase understand, because it shows a process of understanding. Typically, conditions of mental process have in any event one participant speaking to, the person who thinks, sees, enjoys, etc. This participant should consistently be energize and is typically human. It is known as the Senser. From the model over, the senser is she, since it does the sensing process.

\section{c) Perception and its Participant}

In this cognition process is shown by the phrase of verb, like seeing, hearing, smelling, looking and tasting. This perception process may carry one or two or more participants. Based on the concept of mental process, there are two participants carried by the process, they are senser and phenomenon. The circumstance here is optional. Based on the data, only verb "see" is found and the participant is analyzed. See the example below:

I could see the helicopter stop and shoot directly at the house (15-10:6)

The example uses the mental process of perception in the clause I could see the helicopter stop and shoot directly at the house. Here the mental process of perception is expressed by the verb phrase could see, because it shows a process of seeing. The participant which is filled by noun phrase $I$ plays the role of senser and comes before the mental process. It can be categorized as senser because the noun phrase $I$ experiences the process of seeing. This clause 
also has the participant which comes after the process. The participant which comes after mental process is filled by the clause the helicopter stop which plays the role as phenomenon because it is the thing which is seen by the senser $I$.

\subsection{Relational Process and its Participant}

Identifying processes are processes which establish identity, while attributive process are process which assign a quality. The participants who are used in the relational process carry their own participants. The participants which are used in the relational process are attributive, carrier, identified (token), and identifier (value). Like the other type of process, here the circumstance may come as optional element. The explanation is described below.

\section{a) Intensive}

In type of Intensive, the relationship between the two terms is one of sameness; the one 'is' the other. The problem is to specify what exactly this means. It comes into two modes; the attributive and the identifying mode.

\section{b) Relational Process with Attributive}

Based on data taken from The Bali Times News, it was found the example shows the process of intensive as attributive mode.

Herbalife become title sponsor of the 8th Edition of the Bali International Triathlon set for Sunday, October 25, 2015. (10-15:16).

Based on the concept of an intensive process, the example above shows the attributive mode intensive process which is filled by the verb phrase become in the clause Herbalife become title sponsor of the 8th Edition of the Bali International Triathlon set for Sunday, October 25, 2015, because it is known by the process of being. Before the process there is a participant in the form of noun phrase Herbalife. It belongs to carrier, because it carries attribute of quality. Title sponsor of the 8th Edition of the Bali International Triathlon plays the role as attribute, because is realized as a noun phrase, one of that is indefinite; it has as head a noun or an adjective, but not a pronoun.

\section{c) Relation Process with Identifying}

Based on data taken from The Bali Times News, it was found the example shows the process of intensive as identifying process. The example is exampled below:

Tenganan, an old village on the island, also known as Bali Aga village, has a unique traditional ceremony that is banana war or mesabatan biu. (10-15: 11)

The example above shows the process of intensive as the identifying mode. It is expressed by the verb phrase is in the clause is banana war or mesabatan biu, because Here the noun phrase Tenganan, an old vilage on the island, also known as Bali Aga village, has a unique traditional ceremony that can be categorized as identified (token) because it is identified by the noun phrase banana war or mesabatan biu. The noun phrase banana war or mesabatan biu is the second participant belongs to identifier. The noun phrase banana war or mesabetan biu give identity to the participant Tenganan Village. 


\section{d) Circumstantial}

Circumstantial is the relationship between the two-term is one of time, place, manner, cause, accompaniment, matter or role. It comes into two modes, attributive and identifying. In this relation, the circumstantial may be expressed by participants or processes. Based on the analysis, it was found only circumstantial relation with attributive. The participants who are carried by the process, they are carrier and value. It can be seen in the following example: 15:13)

The box set will include four hours of previously unreleased video on three DVDs. (10-

The clause is also formed by circumstance process. It is realized by the verb phrase will include. It carries two participants, the first participant is realized by the noun phrase The box and the second participant is realized by prepositional phrase four hours of previously unreleased video on three DVDs. The box plays as the role as a carrier. The circumstance of time is filled by prepositional phrase four hours of previously unreleased video on three DVDs. It plays the role as value which identifies the carrier.

\section{e) Possessive}

In this type, the relationship between the two terms is one of ownership; one entity possesses another. It comes into two modes attributive and identifying. It can be seen in the following example.

Denpasar Inti pro has hundreds of property listings that are ready to be marketed. (10-15:8)

The example above shows the relationship between possessive. It is expressed by verb phrase has, because it shows the relationship between two terms that one of ownership; one entity possesses another. It carries two participants. The first participant comes before the verb phrase has is The Government. It plays the role as carrier which carries the attribute to improve law enforcement in the country to restore public confidence. It is in the form of noun phrase which plays the role as attribute.

\subsection{Verbal Process and its Participant}

Verbal process is processes of saying, or emblematically flagging. The mandatory member is Sayer, and the discretionary members are target, recipient and verbiage. Sayer is the sign source. Collector and target are discretionary members. The example of the participant as sayer and verbiage found in verbal process is explained below:

The Borobudur temple was "much more beautiful than Angkor Wat in Cambodia", he remarked. (10-15:5)

The example above, it can be seen the verbal process found in the text. It is indicated by verb phrase remarked, because it represents process of saying. It carries two participants, he and The Borobudur temple was "much more beautiful that Angkor Wat in Cambodia". The noun phrase $H e$ plays the role as sayer which does the activity of talking. The noun phrase The Borobudur temple was "much more beautiful that Angkor Wat in Cambodia". It plays the role as verbiage, which shows a message or the content announced by the sayer.

\subsection{Existential process and its Participant}

Existential processes are communicated by action words of existing, for instance, "be" and "exist" and there is one member known as exist, and there is one member known as existent. 
The existent might be a wonder of any sort, and regularly, truth be told and a function. It can be seen in the following example:

On the other hand, there are a number of projects that needs special study. (10-15:2)

The example above belongs to the existential process because are shows the existence of something meanwhile there has no representational function in existential process. There is one participant here, known as the existent. The existent in this clause is a number of projects.

\section{Conclusion}

Grounded by the analysis of the process types in the text, it can be drawn the conclusions. It was found five types of processes. Those are a material, mental, verbal, relational and existential process. The first type of process found in The Bali Times is material process. This material process is expressed by verb phrase won, present, has set, will build, will sell, has been wowing, have been pocketed, has given, took over, will release, hosted, played, will be donated, was dedicated, will convene, and was held. This process uses different participants which depend on the kinds of verb phrase used. The material process which is expressed by the verb phrase won, present, has set, will build, will sell, has been wowing, have been pocketed, will switch, took over, will release have the participant as actor and goal. The material process which expressed by the verb phrase hosted, played has the participant actor and range. The material process which expressed by the verb phrase will be donated and was dedicated have participant goal and recipient. The material process which expressed by the verb phrase will convene, and was held have participants goal and prepositional phrase place. The second type of process found in The Bali Times is mental process. The mental process found in The Bali Times is expressed by the verb phrase felt and lauded (affection), understand, believed, think, know (cognition) and see (perception) have the participant as senser and phenomenon. The third types of process found in The Bali Times are relational process. The relational process found in The Bali Times is expressed by the verb phrase become, seems, has been(intensive as attributive), is (intensive as identifying), will include, has been and be (circumstantial), has (possessive). Based on the attributive mode participant of relational process are as carrier and attribute. Based on the identifying mode, participants of relational process are identified (token) and identifier (value). The fourth type of process found in The Bali Times is verbal processes which are expressed by the verb phrase have confirmed, remarked, said, affirmed, explained, announced and stated. The participants of verbal processes are sayer and verbiage. The last type of process is existential process which is expressed by the verb phrase $b e$. In this case the process has only one participant as an existent.

\section{References}

[1] M. Halliday, An Introduction to Functional Grammar. New York: Routledge, 1985.

[2] M. Zhao and Y. Zhang, "Transitivity Analysis of American President Donald Trump's Inaugural Address," International Journal of Liberal Arts and Social Science, vol. 6, no. 2, p. 28, 2017.

[3] A. Wulansari and S. Waluyo, "Meaning Behind the Poem : an Analysis of Transitivity of poems in," Prosiding Prasasti, no. 2014, pp. 171-176, 2016.

[4] M. R. Bustam, “Analyzing Clause By Halliday'S Transitivity System," Jurnal Ilmu Sastra, vol. 6, no. 1, pp. 22-34, 2011. 
